\title{
Real-world evidence to guide healthcare policies in oncology
}

\author{
Marco Donia ${ }^{1}$, Steen Werner Hansen ${ }^{2}$ and Inge Marie Svane ${ }^{1}$ \\ ${ }^{1}$ National Center for Cancer Immune Therapy (CCIT-DK), Department of Oncology, Herlev, Denmark \\ ${ }^{2}$ Head Office, Herlev and Gentofte Hospital, Herlev, Denmark \\ Correspondence to: Marco Donia, email: marco.donia@regionh.dk \\ Inge Marie Svane, email: inge.marie.svane@regionh.dk
}

Keywords: real-world evidence; real-world data; clinical trial eligibility

Received: June 02, $2019 \quad$ Accepted: June 19, $2018 \quad$ Published: July 16, 2019

Copyright: Donia et al. This is an open-access article distributed under the terms of the Creative Commons Attribution License 3.0 (CC BY 3.0), which permits unrestricted use, distribution, and reproduction in any medium, provided the original author and source are credited.

\section{ABSTRACT}

Randomized controlled clinical trials (RCTs) in oncology enroll patients who meet strict protocol-specified criteria. Many of these criteria overlap across multiple RCTs. A vast proportion of patients with metastatic cancer do not meet such criteria. Hence, patient populations encountered in clinical practice are essentially different from RCTpopulations, questioning the representativeness of these trials. A real-world evidence approach, using data from clinical practice, is increasingly employed to complement the information on drug safety and efficacy obtained from traditional clinical trials.

\section{INTRODUCTION}

The application of novel treatments to the broad real-world population of patients with a certain cancer disease often results in poorer outcomes than expected from pivotal clinical trials. In extreme cases, evidence from randomized controlled trials (RCT) $[1,2]$ appeared not to be applicable to the global real-world population [3].
The differences in outcome between RCT- and real-world population-based oncology studies are often believed to emerge from significant differences in the baseline characteristics of study participants. Strict enrolment criteria prevent a majority of RCTs from representing a sizable proportion of real-world patients, ranging from $35 \%$ to $70 \%$ in non-small cell lung- [4], renal- [5] and colorectal-cancer [6], and melanoma [7].

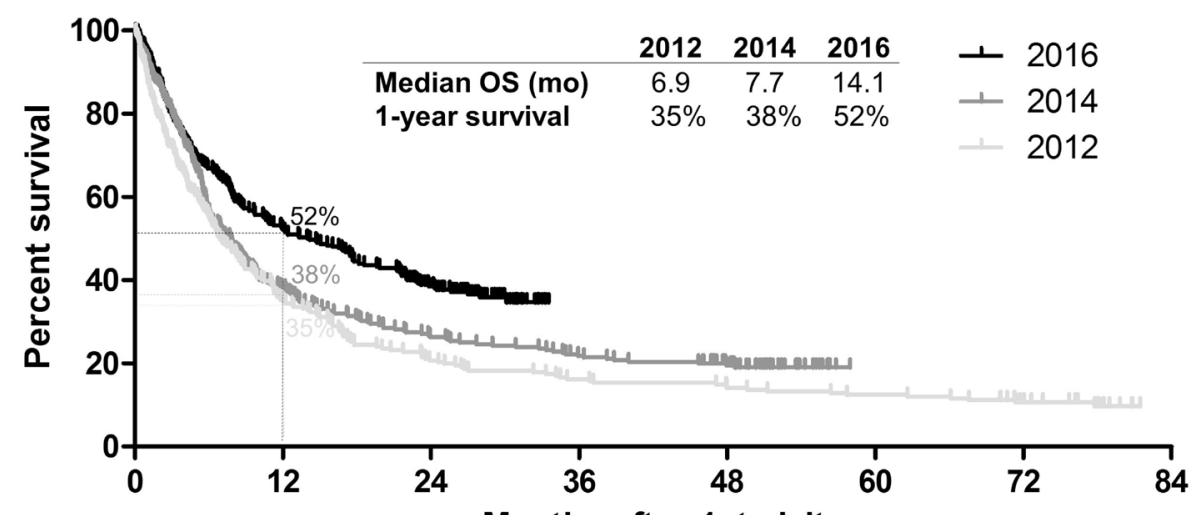

No. at risk

$\begin{array}{lllllllll}2016 & 314 & 165 & 98 & 0 & 0 & 0 & 0 & 0 \\ 2014 & 284 & 110 & 76 & 62 & 43 & 0 & 0 & 0 \\ 2012 & 241 & 86 & 51 & 40 & 35 & 31 & 20 & 0\end{array}$

Figure 1: Survival of patients diagnosed with metastatic melanoma in the pre-modern era (2012), early-modern era (2014) and modern era (2016). Kaplan-Meier plot showing the survival of all patients diagnosed with melanoma, not amenable to surgery or other local treatment, in the whole population of Denmark in the calendar years 2012, 2014 and 2016. mo: months. 
Given these important differences between RCT and real-world populations, the recent approval of numerous new treatments - with their associated high monetary costs and risks of toxicities - have led to a quickly increasing interest in the real-world evidence of the efficacy and safety of such therapies. Currently, a growing number of regulatory bodies, professional societies, and patient organizations support the use of real-world evidence for post-approval recommendations, health technology assessment, reimbursement policies and development of treatment guidelines. Currently, the broadest real-world evidence can be obtained from geographically defined whole population-based studies. These conditions may be satisfied by whole-population retrospective studies conducted within entire countries or regions with proven quality of data registration, such as those that are commonly carried out in Denmark [8].

We have recently analyzed the differences in realworld outcome of all patients with metastatic melanoma diagnosed across Denmark in the pre-modern era (calendar year 2012, when BRAF-inhibitors but not first line immune checkpoint inhibitors where available), early-modern era (2014, first-line anti-CTLA-4 available) and modern era (2016, first line anti-PD-1 and MEK-inhibitors available) [9]. Despite similar baseline characteristics (data not shown), the survival outcome of the global metastatic melanoma population was significantly improved in 2016 versus 2014 (hazard ratio, HR for death $0.73,95 \%$ CI $0.60-0.88 ; p=$ 0.0013 ) or 2012 (HR $0.61,95 \%$ CI $0.50-0.75 ; p<0.0001$ ), with no major differences in 2014 versus 2012 (HR 0.85, 95\% CI 0.70-1.03; $p=0.0935$ ) (Figure 1). Importantly, we were able to discern a sub-group of real-world patients who had very similar baseline characteristics to patients enrolled in pivotal clinical-trials ("trial-like"), from a subgroup of patients that was not represented in such trials because they failed to meet one or more key criteria for enrolment ("trialexcluded"). As reported in our recent study [9], both groups had an improved outcome in 2016 versus 2014 or 2012. Hence, the introduction of novel treatments in 2016 led to a better survival outcome of the broad population of patients diagnosed with metastatic melanoma in the real-world. This largely confirms the results of phase III registration trials.

In conclusion, although RCTs are still the goldstandard practice to evaluate the efficacy (and safety) of a given treatment intervention versus the standard-of-care, real-world studies are critical for understanding whether the results from such RCTs are applicable to the broader population of patients affected by a certain disease. This is particularly true in oncology, where up to twothirds of real-world patients [4-7] are not represented by current RCTs. As recently highlighted by a joint research statement of the American Society of Clinical Oncology (ASCO) and the Friends of Cancer Research [10], future RCTs should take these issues into account and broaden eligibility criteria to maximize the generalizability of results. Healthcare policies should be guided by data that are representative and generalizable to the global population of patients to whom a given treatment intervention offer is directed. To this end, we encourage healthcare regulators and reimbursement agencies to request such data. These data will be readily available, if future RCTs will broaden inclusion criteria. Nonetheless, it is likely that many future drug approvals will continue to be based on current types of unrepresentative RCTs; thus, we suggest that regulators demand a systematic follow up on expanded populations treated in the real-world on expanded populations in order to measure the true benefit of a certain treatment intervention. The recent European Medicine Agency's Initiative for Patient Registries, created to optimize the continuing benefit-risk evaluation of medicinal products (already in use for CAR-T cel therapy post-authorisation follow up), is an important step forward in this direction.

\section{CONFLICTS OF INTEREST}

MD received honoraria for lectures from Bristol-Myers Squibb, MSD, Roche, Novartis, Sanofi Genzyme, and Astra Zeneca. IMS received honoraria for consultancies and lectures from Novartis, Roche, Merck, Bristol-Myers Squibb, and Incyte.

\section{FUNDING}

This work was in part supported by Bristol-Myers Squibb, Roche, Novartis, and MSD through economic support to the Danish Metastatic Melanoma Database (DAMMED); and by Herlev and Gentofte Research council through a stipend to MD. The funding bodies did not have any other role in the study.

\section{REFERENCES}

1. Llovet JM, Ricci S, Mazzaferro V, Hilgard P, Gane E, Blanc JF, de Oliveira AC, Santoro A, Raoul JL, Forner A, Schwartz M, Porta C, Zeuzem S, et al, and SHARP Investigators Study Group. Sorafenib in advanced hepatocellular carcinoma. N Engl J Med. 2008; 359:378-90. https://doi.org/10.1056/ NEJMoa0708857. [PubMed]

2. Cheng AL, Kang YK, Chen Z, Tsao CJ, Qin S, Kim JS, Luo R, Feng J, Ye S, Yang TS, Xu J, Sun Y, Liang H, et al. Efficacy and safety of sorafenib in patients in the AsiaPacific region with advanced hepatocellular carcinoma: a phase III randomised, double-blind, placebo-controlled trial. Lancet Oncol. 2009; 10:25-34. https://doi.org/10.1016/ S1470-2045(08)70285-7. [PubMed]

3. Sanoff HK, Chang Y, Lund JL, O'Neil BH, Dusetzina SB. Sorafenib Effectiveness in Advanced Hepatocellular Carcinoma. Oncologist. 2016; 21:1113-20. https://doi. org/10.1634/theoncologist.2015-0478. [PubMed] 
4. Yoo SH, Keam B, Kim M, Kim TM, Kim D, Heo DS. Generalization and representativeness of phase III immune checkpoint blockade trials in non-small cell lung cancer. Thorac Cancer. 2018; 9:736-744. https://doi. org/10.1111/1759-7714.12641. [PubMed]

5. Heng DYC, Choueiri TK, Rini BI, Lee J, Yuasa T, Pal SK, Srinivas S, Bjarnason GA, Knox JJ, Mackenzie M, Vaishampayan UN, Tan MH, Rha SY, et al. Outcomes of patients with metastatic renal cell carcinoma that do not meet eligibility criteria for clinical trials. Ann Oncol. 2014; 25:149-54. https://doi.org/10.1093/annonc/mdt492. [PubMed]

6. Sorbye H, Pfeiffer P, Cavalli-Björkman N, Qvortrup C, Holsen MH, Wentzel-Larsen T, Glimelius B. Clinical trial enrollment, patient characteristics, and survival differences in prospectively registered metastatic colorectal cancer patients. Cancer. 2009; 115:4679-87. https://doi. org/10.1002/cncr.24527. [PubMed]

7. Donia M, Kimper-Karl ML, Hoyer KL, Bastholt L, Schmidt H, Svane IM. The majority of patients with metastatic melanoma are not represented in pivotal phase III immunotherapy trials. Eur J Cancer. 2017; 74:89-95. https://doi.org/10.1016/j.ejca.2016.12.017. [PubMed]

8. Frank L. When an entire country is a cohort. Science. 2000; 287:2398-9. https://doi.org/10.1126/science.287.5462.2398. [PubMed]

9. Donia M, Ellebaek E, Øllegaard TH, Duval L, Aaby JB, Hoejberg L, Køhler UH, Schmidt H, Bastholt L, Svane IM. The real-world impact of modern treatments on the survival of patients with metastatic melanoma. Eur J Cancer. 2019; 108:25-32. https://doi.org/10.1016/j.ejca.2018.12.002. [PubMed]

10. Kim ES, Bruinooge SS, Roberts S, Ison G, Lin NU, Gore L, Uldrick TS, Lichtman SM, Roach N, Beaver JA, Sridhara R, Hesketh PJ, Denicoff AM, et al. Broadening eligibility criteria to make clinical trials more representative: american society of clinical oncology and friends of cancer research joint research statement. J Clin Oncol. 2017; 35:3737-44. https://doi.org/10.1200/JCO.2017.73.7916. [PubMed] 